\title{
Kinematic Wave Theory for Transient Bed Sediment Waves in Alluvial Rivers
}

\author{
Vijay P. Singh ${ }^{1}$ and Gokmen Tayfur ${ }^{2}$
}

\begin{abstract}
Transient bed sediment waves in alluvial rivers have been described using a multitude of hydraulic formulations. These formulations are based on some form of the St. Venant equations and conservation of mass of sediment in suspension and in bed. Depending on the assumptions employed, a hierarchy of formulations is expressed. These formulations in the literature employ uncoupled, semicoupled, or fully coupled transport models treating the sediment waves as either hyperbolic (dynamic wave) or parabolic (diffusion wave). It is, however, hypothesized that the movement of bed sediment waves in alluvial rivers can be described as a kinematic wave. Kinematic wave theory employs a functional relation between sediment transport rate and concentration and a relation between flow velocity and depth. This study summarizes the hierarchy of the formulations while emphasizing the kinematic wave theory for describing transient bed sediment waves. The applicability of the theory is shown for laboratory flume data and hypothetical cases.
\end{abstract}

DOI: 10.1061/(ASCE)1084-0699(2008)13:5(297)

CE Database subject headings: Rivers; Sediment; Kinematic wave theory; Hydraulics; Alluvial fans.

\section{Introduction}

Understanding the behavior of alluvial rivers is not only essential for river training works but also is important for environmental, ecological, and geomorphologic studies. Fundamental to this understanding is the evolution of channel morphology, in that riverbed elevation is the main component. Bed forms or bed material waves are normally seen as transient zones of sediment accumulation on the channel bed. These result from a strong interaction between water flow hydraulics, sediment transport, and river morphology.

Mainly, three types of bed forms occur under different flow and alluvium conditions: ripples, dunes, and antidunes. Ripples that are, typically, small (less than $30 \mathrm{~cm}$ in length) occur in beds of rather fine material at low sediment transport rates. The typical shape of a ripple is presented in Fig. 1. The upstream face is generally concave, the higher part is convex, and the downstream face is short and slopes downward at approximately the angle of repose (Fig. 1). The material is eroded from the upstream face and deposited over the downstream face, causing migration of the bed form. Ripples migrate downward, maintaining their general size and shape. Their speed of migration is several orders of magnitude smaller than the water flow velocity. Dunes have the same general shape as ripples (Fig. 1) but they are larger-ranging in

${ }^{1}$ Caroline and William N. Lehrer Distinguished Chair in Water Engineering and Professor, Dept. of Biological and Agricultural Engineering, Texas A\&M Univ., Scoates Hall, 2117 TAMU, College Station, Texas 77843-2117. E-mail: vsingh@tamu.edu

${ }^{2}$ Professor, Dept. of Civil Engineering, Izmir Institute of Technology, Gulbahce Kampus, Urla, Izmir, 35340, Turkey. E-mail: gokmentayfur@ iyte.edu.tr

Note. Discussion open until October 1, 2008. Separate discussions must be submitted for individual papers. To extend the closing date by one month, a written request must be filed with the ASCE Managing Editor. The manuscript for this paper was submitted for review and possible publication on November 13, 2006; approved on May 22, 2007. This paper is part of the Journal of Hydrologic Engineering, Vol. 13, No. 5, May 1, 2008. CASCE, ISSN 1084-0699/2008/5-297-304/\$25.00. length from several meters to hundreds of meters. Flow patterns, sediment transport, and the downstream migration of dunes are very similar to those observed for ripples. However, typical dune lengths are substantially greater than the flow depth, while the lengths of ripples are more likely to be less than the flow depth. In addition, ripples occur as soon as there is any particle movement, provided there is local irregularity in the bed to start their formation. On the other hand, dunes develop simultaneously all over the bed when conditions are right for their growth. Antidunes occur only in fast flowing streams, where the Froude number, $\mathrm{F}>0.8$. They have sharp crests and rounded troughs, and upstream and downstream faces are almost symmetrical. A typical shape of an antidune is given in Fig. 2. The water surface exhibits a profile of standing waves. These bed forms are not stable in time. They may remain fixed in space or may migrate upstream but seldom move downstream.

The physical processes governing the changes in river bed forms (and/or bed material waves) are very complex and vary both in spatial and temporal domains. Although alluvial river processes, in general, evolve in long time periods, some extreme events like flash flood or dam break or dike failure floods may cause extensive changes over relatively short periods of time, in the order of a few hours. In any case, analysis of bed forms must take into account the relationships between: (1) sediment transport and fluid over the bed form; (2) fluid flow and the shape of the bed form profile; and (3) bed form profile and sediment transport. These relationships are often derived using mathematical models on a short or long time scale. Typically, these models are based on the conservation of mass for water and sediment and the conservation of momentum for water flow as well as a hydraulic resistance relation and sediment transport function. The hydraulic resistance relation is generally expressed by the Chezy or Mannings equation.

The sediment transport function is expressed as a function of flow variables that are obtained by the solution of full dynamic or diffusion wave equations. The bed sediment wave movement has mostly been treated as having the properties of a diffusion or dynamic wave. Accordingly, a direct variation is assumed be- 


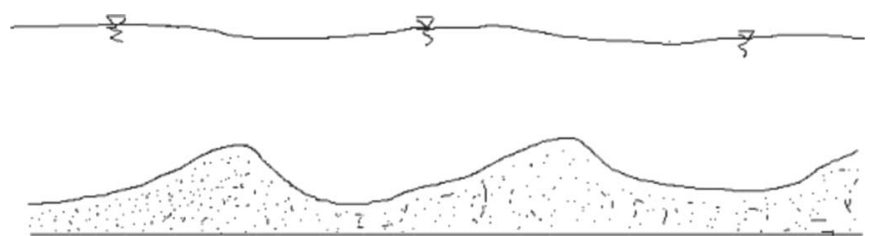

Fig. 1. Dune (or ripple) profile

tween bed level (i.e., transported sediment concentration) and flow variables. This implies that as flow variables increase (or decrease) the bed level increases (or decreases) with no dependence on the amount of the sediment concentration in the movable bed layer or with no limit to the elevation of bed level. However, the experimental studies of Langbein and Leopold (1968) on bead movement in a flume, rock and gravel movement in a stream, and sand movement in pipes and flumes indicate that the evolution and movement of bed forms that are composed of discrete particles can be described by the kinematic wave theory by which the sediment transport function can be expressed as a function of sediment concentration, rather than the flow variables.

The objective of this study is to present the hierarchy of the existing models based on dynamic and diffusion waves and then introduce the kinematic wave theory model for describing the transient sediment waves in alluvial river beds. The plausibility of the kinemetic wave theory model is shown using measured flume data and hypothetical cases.

\section{Mathematical Formulations}

A bed sediment transport can be represented by a two-layer system as shown in Fig. 3. In this system there is a water flow layer in which there can be suspended sediment and there is a movable bed layer in which sediment has a porosity. There may be exchange of sediment between these two layers, depending upon the flow transport capacity and sediment rate in suspension. The movement of water and sediment can be described mathematically by the equations of momentum and conservation of water and sediment. Unsteady, nonuniform, and nonequilibrium transport equations in one dimension can, in general, be expressed as

$$
\begin{gathered}
\frac{\partial\left(\rho_{m} u h B\right)}{\partial t}+\frac{\partial\left(\rho_{m} u^{2} h B\right)}{\partial x}+g B h \frac{\partial\left(\rho_{m} h\right)}{\partial x}+g \rho_{m} B h \frac{\partial z}{\partial x} \\
=g \rho_{m} B h\left(S_{o}-S_{f}\right)+\rho_{m} u_{l}\left(q_{l s}+q_{l w}\right) \\
\frac{\partial[B h(1-c)]}{\partial t}+\frac{\partial[B h u(1-c)]}{\partial x}+p \frac{\partial(B z)}{\partial t}+\frac{\partial\left(B q_{b w}\right)}{\partial x}=q_{l w} \\
\frac{\partial(B h c)}{\partial t}+\frac{\partial(B h u c)}{\partial x}=q_{\mathrm{lsus}}+\frac{B}{\rho_{s}}\left[E_{z}-D_{c}\right] \\
(1-p) \frac{\partial(B z)}{\partial t}+\frac{\partial\left(B q_{b s}\right)}{\partial x}=q_{\mathrm{lbed}}+\frac{B}{\rho_{s}}\left[D_{c}-E_{z}\right]
\end{gathered}
$$

where $u=$ mean flow velocity $(L / T) ; h=$ flow depth $(L)$; $c=$ volumetric suspended sediment concentration $\left(L^{3} / L^{3}\right)$; $B=$ channel width $(L) ; \rho_{m}=$ mean density of water-sediment

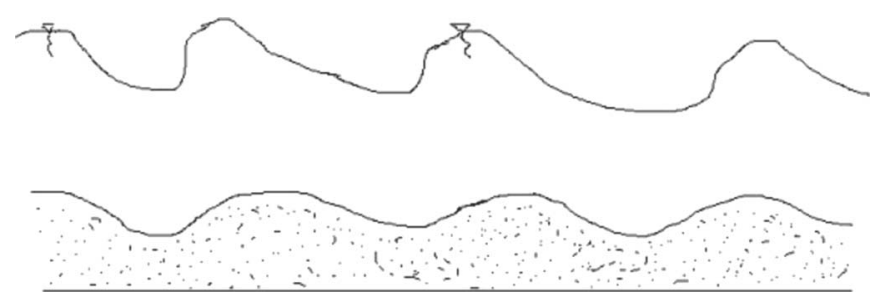

Fig. 2. Antidune profile

mixture $\left(M / L^{3}\right)\left[\rho_{m}=\rho_{w}+\left(\rho_{s}-\rho_{w}\right) c\right] ; \rho_{w}=$ mean density of water $\left(M / L^{3}\right) ; \rho_{s}=$ mean density sediment $\left(M / L^{3}\right) ; z=$ movable bed layer height $(L) ; q_{b w}=$ water flux in the mobile bed layer $\left(L^{2} / T\right)$; $p=$ porosity of sediment in the bed layer $\left(L^{3} / L^{3}\right)$; $g=$ gravitational acceleration $\left(L / T^{2}\right) ; S_{o}=$ channel bed slope; $S_{f}=$ friction slope; $u_{l}=$ longitudinal component of lateral inflow discharge velocity; $q_{\mathrm{ls}}=$ lateral sediment discharge $\left(L^{2} / T\right)$ $\left[q_{\mathrm{ls}}=q_{\mathrm{lsus}}+q_{\mathrm{lbed}}\right] ; \quad q_{\mathrm{lsus}}=$ lateral suspended sediment $\left(L^{2} / T\right)$; $q_{\text {lbed }}=$ lateral bed load sediment $\left(L^{2} / T\right) ; q_{\mathrm{lw}}=$ lateral flow discharge $\left(L^{2} / T\right) ; q_{b s}=$ sediment flux in the movable bed layer $\left(L^{2} / T\right)$; $E_{z}=$ entrainment rate (detachment rate) $\left(M / L^{2} / T\right)$; and $D_{c}=$ deposition rate $\left(M / L^{2} / T\right) ; x=$ independent variable for longitudinal distance; and $t=$ independent variable of time.

Eq. (1) stands for the water flow momentum and Eqs. (2)-(4) are for the conservation of mass for water in both the layers, sediment in suspension, and sediment in the bed layer, respectively. The last terms on the right-hand sides of Eqs. (3) and (4) show that there is an exchange of sediment between the water flow layer and bed layer, depending upon the availability of sediment and flow transport capacity. The system of Eqs. (1)-(4) is a fully coupled model, involving the variables of flow and sediment dynamics in each equation.

In the above formulation, the nonequilibrium effects are considered through the entrainment $\left(E_{z}\right)$ and the deposition $\left(D_{c}\right)$ terms given on the right-hand sides of Eqs. (3) and (4). These terms are, as will be presented later, expressed as functions of flow and sediment characteristics. Thus, depending upon the transport capacity of the flow, temporally and spatially varying deposition and entrainment might take place interchangeably. Pianese (1994), Mohammadian et al. (2004), and Singh et al. (2004), on the other hand, employed a lag equation in order to consider the nonequilibrium effects in the transport of bed material load.

Eqs. (1)-(4) constitute the coupled dynamic wave formulation for sediment-laden water flow under nonequilibrium conditions. Due to the difficulties in the solutions of the complete system, simpler versions of Eqs. (1)-(4) have commonly been employed in the literature. Simplifications have involved omitting terms in the momentum equation [Eq. (1)] and/or in the conservation of mass equations [Eqs. (2)-(4)], resulting in a hierarchy of formulations. The simplifications have involved the following:

1. $B=$ constant;

2. $\rho_{m}=\rho_{w}$ in Eq. (1) [i.e., $c=0.0$ in Eq. (1)];

3. $u_{l}=0.0$ (i.e., no lateral fluxes); and

4. $E_{z}=D_{c}$ (i.e., equilibrium case).

These assumptions resulted in the following simple dynamic wave formulation: 


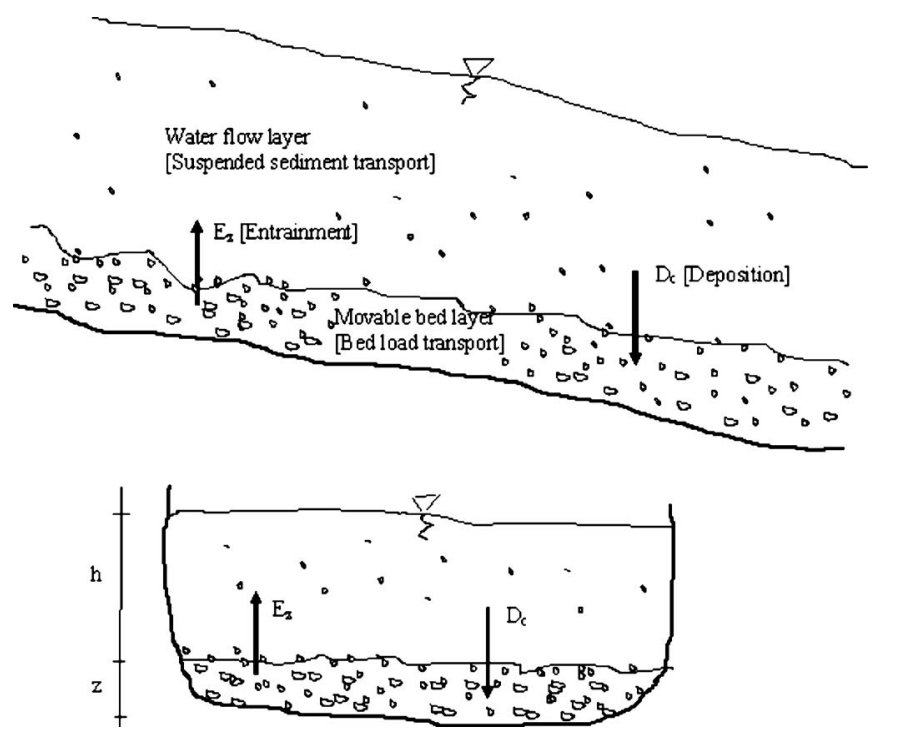

Fig. 3. Two-layer system

$$
\begin{gathered}
\frac{\partial u}{\partial t}+u \frac{\partial u}{\partial x}+g\left(\frac{\partial h}{\partial x}+\frac{\partial z}{\partial x}\right)=g\left(S_{o}-S_{f}\right) \\
\frac{\partial h(1-c)}{\partial t}+\frac{\partial h u(1-c)}{\partial x}+p \frac{\partial z}{\partial t}=\frac{q_{l w}}{B} \\
\frac{\partial h c}{\partial t}+\frac{\partial h u c}{\partial x}+(1-p) \frac{\partial z}{\partial t}+\frac{\partial q_{b s}}{\partial x}=\frac{q_{l s}}{B}
\end{gathered}
$$

Under the second and third assumptions, the effects of suspended sediment concentration and lateral fluxes on momentum are ignored. Under the last assumption, there is no exchange of sediment between the movable bed layer and water flow layer. In other words, there is equilibrium between the suspended load in the water flow layer and bed load in the movable bed layer. Under the equilibrium condition, Eq. (4) is generally combined with Eq. (3) into a single equation, as expressed by Eq. (7), in the literature. Eqs. (5)-(7) were employed by Ching and Cheng (1964), Mahmood (1975), and Pianese (1994). Also, Eqs. (5)-(7) were employed by de Vries (1975), who ignored the suspended sediment concentration in Eq. (6) and Mohammadian et al. (2004), who ignored the bed sediment flux in Eq. (7). Note that although the simple dynamic wave approach assumes equilibrium between the two layers it still considers the transport in both layers (two-layer system). This simple dynamic wave system is still a coupled model through $(\partial z / \partial x)$ in the water flow momentum Eq. (5), $c$, and $[p(\partial z / \partial t)]$ in the conservation of water mass Eq. (6), and flow variables $h$ and $u$ in conservation of sediment mass Eq. (7).

The system of Eqs. (5)-(7) (the simple dynamic wave approximation) has been further simplified in the literature (de Vries 1973; 1975; Ribberink and Van Der Sande 1985; Hotchkiss and Parker 1991; Cao and Carling 2003), resulting in the simple diffusion wave formulation

$$
\begin{gathered}
\left(\frac{\partial h}{\partial x}+\frac{\partial z}{\partial x}\right)=\left(S_{o}-S_{f}\right) \\
\frac{\partial h}{\partial t}+\frac{\partial h u}{\partial x}+p \frac{\partial z}{\partial t}=0 \\
(1-p) \frac{\partial z}{\partial t}+\frac{\partial q_{b s}}{\partial x}=0
\end{gathered}
$$

The same system was employed by Vreugdenhil and de Vries (1973), who ignored the depth gradient and bed-slope terms in Eq. (8). When the simple diffusion wave formulation is compared to the simple dynamic wave approach, it is seen that it models the transport of sediment in clear water (i.e., $c=0.0$ ), and consequently, ignores the temporal and spatial change of sediment storage in the water column [i.e., $(\partial h c / \partial t)=0 ;(\partial h u c / \partial x)=0.0$ ]. Also, it does not consider the effects of local and convective inertia on momentum [i.e., $(\partial u / \partial t)=0.0 ; u(\partial u / \partial x)=0.0]$. In the simple diffusion wave formulation, both the dynamics of water flow in the water flow layer and sediment transport in the movable bed layer (two-layer system) are interlinked through the spatial change of riverbed elevation $(\partial z / \partial x)$ in the momentum equation; evolutionary rate of riverbed elevation $[p(\partial z / \partial t)]$ in the conservation of water mass equation; and the sediment flux in the movable bed layer $\left(q_{b s}\right)$ that is expressed as a function of flow and sediment characteristics. Note, however, that the full diffusion wave formulation would retain the spatial and temporal change of sediment storage in the water column in sediment laden transport under nonequilibrium conditions.

In the case of the full dynamic wave [Eqs. (1)-(4)] or the simple diffusion wave [Eqs. (8)-(10)], the mathematical formulation has been closed by relating the sediment flux in the movable bed layer to the flow variables (sediment transport function) as $q_{s}=\kappa u^{\phi} h^{\eta}$ where $\kappa, \phi$, and $\eta$ are parameters (Mahmood 1975; Ribberink and Van Der Sande 1985; Vreugdenhil and de Vries 1973). In the case of the simple dynamic wave [Eqs. (5)-(7)] or the full diffusion wave approach, the formulation is, in addition to the sediment transport function, closed by relating the suspended sediment concentration in the water flow layer to the flow variables as $c=\delta u^{\chi} h^{\xi}$, where parameters $\delta, \chi$, and $\xi$ are functions of water flow and sediment characteristics (Ching and Cheng 1964; de Vries 1975; Pianese 1994; Cao and Carling 2003). For example, if Velikanov's approach (Ching and Cheng 1964) is employed for relating the suspended sediment concentration to the flow variables, i.e., $c=\left(\varepsilon u^{3} / g v_{f} h\right)$, where $\varepsilon=$ coefficient of sediment transport capacity; $g=$ gravitational acceleration $\left(L / T^{2}\right)$; $v_{f}=$ average fall velocity of sediments $(L / T) ; \delta=\varepsilon /\left(g v_{f}\right) ; \chi=3$; and $\xi=-1$.

The formulations summarized above are all coupled models. Decoupled models solve the flow continuity and momentum equations simultaneously, ignoring the strong interaction between solid and water phases of the flow (Singh et al. 2004). Although some studies (Kassem and Chaudhry 1998; Cui et al. 1996) could not find a significant difference in results produced by the semicoupled (or fully coupled) and decoupled models, Lyn (1987) showed that decoupled models are only valid for cases where changes in boundary conditions are negligible. Cao et al. (2002) further showed that use of uncoupled and/or semicoupled models for simulating aggradation processes can lead to substantial inaccuracies. 


\section{Kinematic Wave Theory}

Assuming a constant channel width with no lateral water and sediment fluxes, the system of Eqs. (1)-(4) (the full dynamic wave) can be simplified as

$$
\begin{gathered}
S_{o}=S_{f} \\
\frac{\partial[h(1-c)]}{\partial t}+\frac{\partial[h u(1-c)]}{\partial x}+p \frac{\partial z}{\partial t}=0 \\
\frac{\partial(h c)}{\partial t}+\frac{\partial(h u c)}{\partial x}=\frac{1}{\rho_{s}}\left[E_{z}-D_{c}\right] \\
(1-p) \frac{\partial z}{\partial t}+\frac{\partial q_{b s}}{\partial x}=\frac{1}{\rho_{s}}\left[D_{c}-E_{z}\right]
\end{gathered}
$$

Eq. (11) implies that, when compared to Eq. (1), the effects of the local and convective inertia, spatial change of water level and channel bed elevation (pressure gradients), suspended sediment concentration, and lateral fluxes on the water flow momentum are ignored, and thus result in the employment of the kinematic wave approximation for the momentum. There are six unknowns: $h, u$, $z, c, S_{f}$, and $q_{b s}$ in Eqs. (11)-(14). In order to close the formulation, two more equations are needed. These equations can be obtained by relating friction slope $\left(S_{f}\right)$ to flow variables $(u, h)$ and relating sediment flux $\left(q_{b s}\right)$ to sediment concentration or bed level $(z)$.

The friction slope can be related to the flow variables, assuming a wide rectangular channel, by the Chezy (or Manning) formulation that results in

$$
u=\alpha h^{\beta-1}
$$

where $\alpha=$ kinematic-wave resistance parameter $\left(L^{0.5} / T\right)$ (Singh 1996); and $\beta=$ exponent. Employing the Chezy equation for the friction slope, $\beta=1.5$ and $\alpha=C_{z} S_{o}^{0.5}$, where $C_{z}=$ Chezy roughness coefficient $\left(L^{0.5} / T\right)$.

Following the work of Langbein and Leopold (1968), the second equation can be obtained by relating the sediment transport rate to the sediment concentration (or bed level) in the movable bed layer. Langbein and Leopold (1968) proposed the following sediment flux-concentration relation:

$$
q_{\mathrm{st}}=v_{s} C_{b}\left[1-\frac{C_{b}}{C_{b_{\max }}}\right]
$$

where $q_{\mathrm{st}}=$ sediment transport rate $(M / L / T) ; C_{b}=$ areal sediment concentration $\left(M / L^{2}\right) ; C_{b \max }=$ maximum areal sediment concentration when transport ceases $\left(M / L^{2}\right)$; and $v_{s}=$ velocity of sediment particles as concentration approaches zero $(L / T)$. Chien and Wan (1999) suggested that for $0.08<d_{s}<10 \mathrm{~mm}$ and $10<h / d_{s}<1550$

$$
v_{s}=u-\frac{\left(u_{c} / 1.4\right)^{3}}{u^{2}}
$$

where $u_{c}=$ critical flow velocity at the incipient sediment motion $(L / T) \cdot u_{c}$ is expressed as a function of particle fall velocity $\left(v_{f}\right)$ and the shear velocity Reynolds number $\left(R^{*}\right)$, and is given by Yang (1996). The expression for particle fall velocity given in Yang (1996) is, in essence, valid for perfect spheres. On the other hand, Dietrich (1982), analyzing a wide range of experimental data, developed an empirical function for particle fall velocity that can also consider the effects of shape and roundness on the particle fall velocity. Tayfur and Singh (2006), however, showed that both the formulations for particle fall velocity yield comparable results in the simulation of transient bed sediment waves in alluvial rivers. As an alternative to Eq. (17), Bridge and Dominic (1984), through a theoretical consideration of the dynamics of bed load motion, developed an expression for grain velocity as a function of skin shear stress that is represented as a shear velocity. Tayfur and Singh (2006), however, showed that both formulations for particle velocity have comparable performances.

The part within the brackets of Eq. (16) decreases as concentration $C_{b}$ increases, reaching zero when $C_{b}=C_{b \max }$. Based on the flume sediment transport experiments of Guy et al. (1966), Langbein and Leopold (1968) suggested a value of $C_{b \max }=245 \mathrm{~kg} / \mathrm{m}^{2}$. Fig. 4 shows a sediment flux-concentration relation, in which the flux increases with concentration until it reaches a maximum value and then starts decreasing. Note that this flux-concentration curve differs greatly from that of water wave. The flux-concentration relation for water wave in channel shows an increasing velocity for increasing concentration (flow depth). On the other hand, in sediment transport, particles interact and their mean speed decreases with increasing concentration.

Sediment flux $\left(q_{b s}\right)$ in Eq. (14) is defined in $\left(L^{2} / T\right)$ and the transport rate $\left(q_{s t}\right)$ in Eq. (16) is defined in $(M / L / T)$. Therefore, one can relate both variables as

$$
q_{\mathrm{st}}=\rho_{s} q_{b s}
$$

The areal concentration can be related to the bed level as

$$
C_{b}=(1-p) z \rho_{s}
$$

Substituting Eqs. (18) and (19) into Eq. (16) results in the following equation relating sediment flux to sediment concentration (bed elevation):

$$
q_{b s}=(1-p) v_{s} z\left[1-\frac{z}{z_{\max }}\right]
$$

where $z_{\max }=$ maximum bed level $(L)$. Note that Eq. (20) implies the kinematic wave approach to the sediment transport in the movable bed layer.

Eqs. (12)-(14), along with Eqs. (15) and (20), form the fully coupled system of equations for modeling the evolution and movement of bed sediment waves under unsteady, nonuniform, and nonequilibrium conditions in alluvial rivers using the kinematic wave theory

$$
\begin{gathered}
\frac{\partial[h(1-c)]}{\partial t}+\frac{\partial[h u(1-c)]}{\partial x}+p \frac{\partial z}{\partial t}=0 \\
\frac{\partial(h c)}{\partial t}+\frac{\partial(h u c)}{\partial x}=\frac{1}{\rho_{s}}\left[E_{z}-D_{c}\right] \\
(1-p) \frac{\partial z}{\partial t}+\frac{\partial q_{b s}}{\partial x}=\frac{1}{\rho_{s}}\left[D_{c}-E_{z}\right] \\
u=\alpha h^{\beta-1} \\
q_{b s}=(1-p) v_{s} z\left[1-\frac{z}{z_{\max }}\right]
\end{gathered}
$$

The system of Eqs. (21)-(25) represents the full kinematic wave formulation for the sediment laden water flow in two-layer system. This formulation can be simplified assuming clear water $(c=0)$ and equilibrium transport $\left(E_{z}=D_{c}\right)$ as 


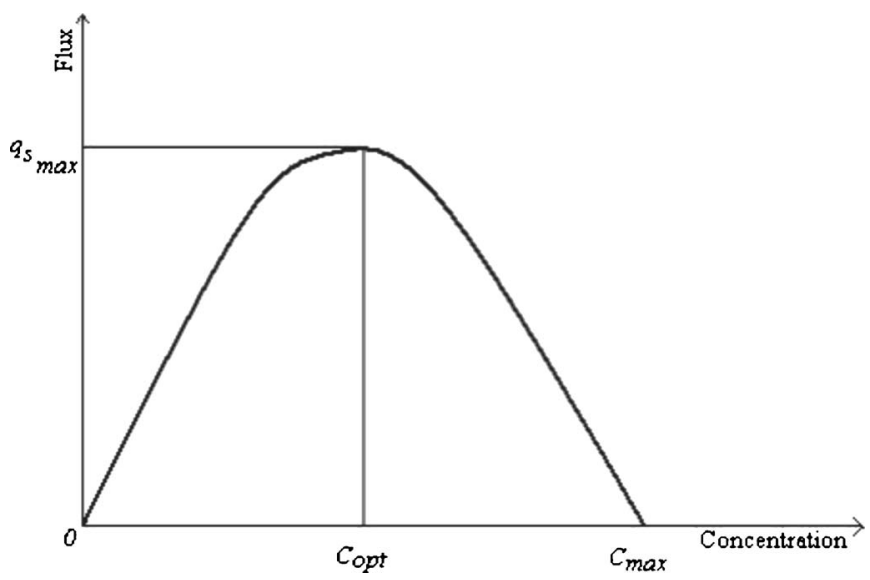

Fig. 4. Sediment flux-concentration curve

$$
\begin{gathered}
\frac{\partial h}{\partial t}+\frac{\partial h u}{\partial x}+p \frac{\partial z}{\partial t}=0 \\
(1-p) \frac{\partial z}{\partial t}+\frac{\partial q_{b s}}{\partial x}=0 \\
u=\alpha h^{\beta-1} \\
q_{b s}=(1-p) v_{s} z\left[1-\frac{z}{z_{\max }}\right]
\end{gathered}
$$

Eqs. (26)-(29) are still a coupled system solving nonuniform and unsteady transient sediment waves in clear water. Substituting Eq. (28) into Eq. (26) and Eq. (29) into Eq. (27) would result in

$$
\begin{aligned}
& \frac{\partial h}{\partial t}+\alpha \beta h^{\beta-1} \frac{\partial h}{\partial x}+p \frac{\partial z}{\partial t}=0 \\
& \frac{\partial z}{\partial t}+v_{s}\left[1-\frac{2 z}{z_{\max }}\right] \frac{\partial z}{\partial x}=0
\end{aligned}
$$

Eqs. (30) and (31) are for modeling transient sediment waves in clear water under equilibrium transport using the kinematic wave theory. Compared to the full kinematic wave formulation, it ignores the temporal and spatial change of sediment storage in the water column due to the $c=0.0$ assumption and assumes that there is no pick up of sediment from the movable bed layer into the suspension. This model still uses a two-layer system such that there is water flow in the water flow and movable bed layer and sediment transport in the movable bed layer. Although it ignores the suspended sediment in the water column, it interlinks the two dynamics of the water flow and sediment transport through the evolutionary rate of riverbed elevation and sediment particle velocity, which is a function of flow and sediment characteristics.

\section{Model Application}

Eqs. (30) and (31) were solved numerically under specified initial and boundary conditions. This study employed an explicit finitedifference method; $h(x, 0)=h_{o}$ and $z(x, 0)=z_{o}$ as initial conditions; and inflow hydrograph $[h(0, t)=h(t)]$ and sedimentograph (or concentration: $z[(0, t)=z(t)]$ as upstream boundary conditions. Since the kinematic wave theory is employed, there was no need to specify any downstream boundary condition, and there- (a)

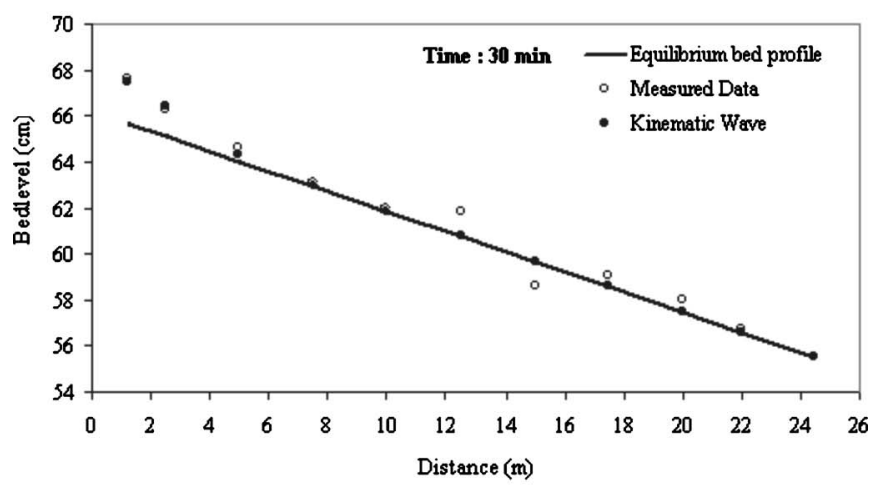

(b)

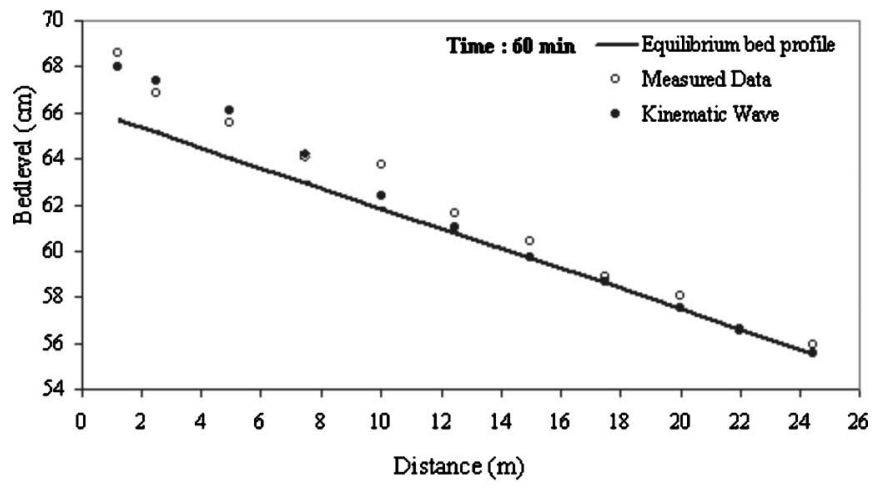

(c)

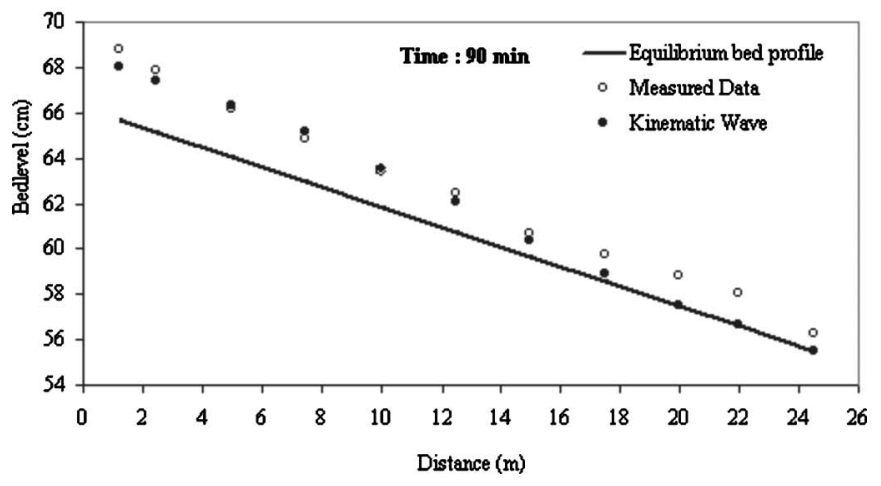

Fig. 5. Simulation of measured bed profiles at (a) $30 \mathrm{~min}$; (b) $60 \mathrm{~min}$; and (c) $90 \mathrm{~min}$

fore, the difference equations for both layers were written not only at the central nodes of the domain but also at the downstream node. Eqs. (30) and (31) were solved simultaneously for each time step to obtain the values of $h$ and $z$ variables in time and space.

\section{Experimental Data}

The kinematic wave (KW) model was tested using the experimental data of Soni (1981), who used a recirculatory and tilting flume of rectangular cross section. The flume was $30.0 \mathrm{~m}$ long, $0.20 \mathrm{~m}$ wide, and $0.50 \mathrm{~m}$ deep. The injected sediment had a median sieve diameter of $d_{50}=0.32 \mathrm{~mm}$ and a specific gravity of $2.65 \mathrm{~g} / \mathrm{cm}^{3}$. Bed elevations were recorded at 11 sections at time intervals varying from 10 to $20 \mathrm{~min}$. The flow was uniform and steady and 


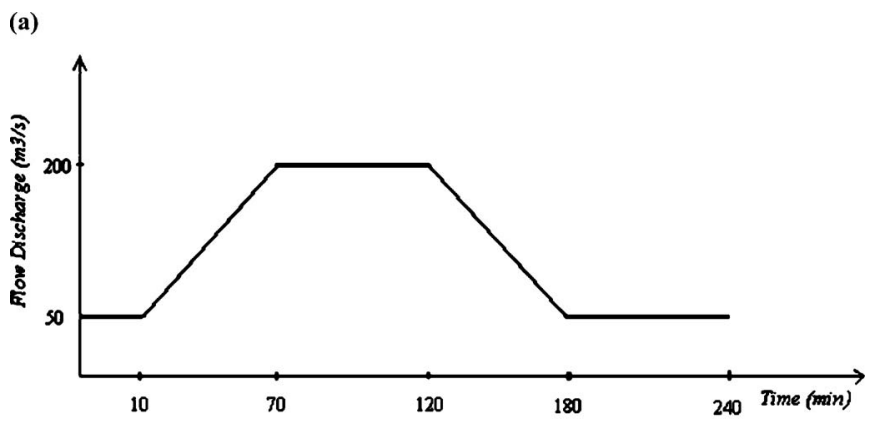

(b)

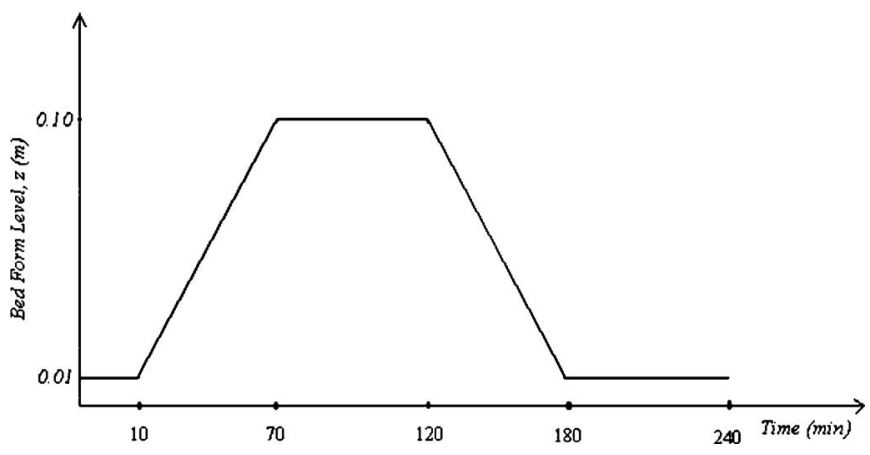

Fig. 6. Inflow: (a) hydrograph; (b) concentration

suspended sediment was negligible in this experiment. Details of the experiment can be obtained from Soni (1981).

Figs. 5(a-c) show, respectively, simulations of sediment waves measured at 30,60, and 90 min during the experimental run that had a constant water flow flux of $Q_{\text {weq }}=0.02 \mathrm{~m}^{3} / \mathrm{s}$; a constant sediment rate of $q_{\mathrm{seq}}=111 \times 10^{-6} \mathrm{~m}^{2} / \mathrm{s} ; S_{o}=0.00212$ (bed slope); $h_{o}=0.092 \mathrm{~m}$ (uniform flow depth) and an excess sediment rate of $\Delta q_{s}=0.9 q_{\text {seq. }}$. As seen in Fig. 5, at each time the model satisfactorily simulated the measured data. The earlier parts of the sediment waves were closely captured by the model. In simulations at 60 and $90 \mathrm{~min}$, the model-predicted transient profiles were slightly ahead of the measured ones in reaching the equilibrium bed profile. The overall computed error measures for simulations in Fig. 5 are MSE $=0.48 \mathrm{~cm}$, RMSE $=0.62 \mathrm{~cm}$, and $R^{2}=0.98$, implying a satisfactory performance of the kinematic wave model. Tayfur and Singh (2006) also satisfactorily simulated other experimental data sets of Soni (1981). They also compared the performance of kinematic wave theory model against the diffusion wave model in simulating experimental data of Soni (1981) and pointed out the plausibility of the KW model.

\section{Hypothetical Cases}

The kinematic wave model was also applied to hypothetical cases assuming an inflow hydrograph and an inflow concentration at the upstream end of the channel, as shown in Fig. 6. The channel was assumed to have a 1,000 m length, $20 \mathrm{~m}$ width, 0.0025 bed slope, and a Chezy roughness coefficient $C_{z}=50 \mathrm{~m}^{0.5} / \mathrm{s}$. The sediment was assumed to have a specific density $\gamma_{s}=2,650 \mathrm{~kg} / \mathrm{m}^{3}$, and a diameter $d_{s}=0.32 \mathrm{~mm}$.

Fig. 7 presents sediment waves during the rising limb ( $t=40 \mathrm{~min})$, equilibrium $(t=100 \mathrm{~min})$, recession limb $(t=160 \mathrm{~min})$, and postrecession $(t=220 \mathrm{~min})$ limb of the inflow hydrograph and concentration, respectively. It is seen that bed

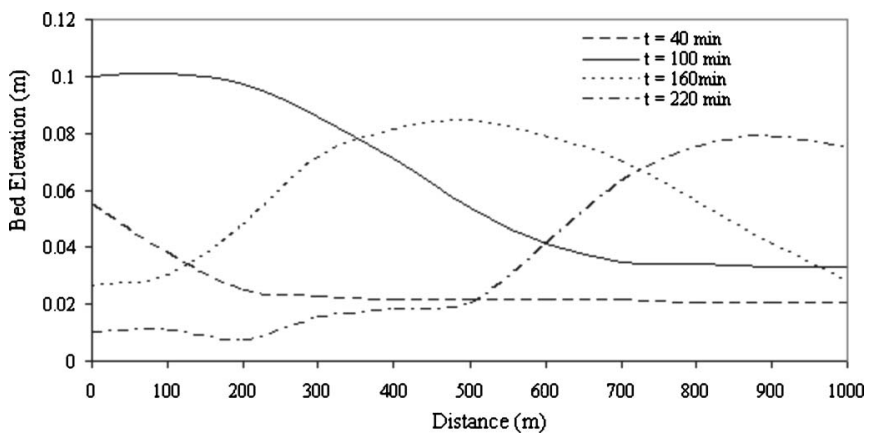

Fig. 7. Transient bed form profiles during rising ( $t=40 \mathrm{~min}$ ); equilibrium ( $t=100 \mathrm{~min})$; recession $(t=160 \mathrm{~min})$; and postrecession $(t=220 \mathrm{~min})$ periods of inflow hydrograph and concentration

elevation gradually increases as the inflow concentration increases at the upstream end of the channel during the rising limb of the inflow concentration. For the period corresponding to the equilibrium feeding of the sediment at the upstream end of the channel, the bed elevation continues to increase in the $70 \%$ of the channel length. During the recession limb of the inflow concentration, as the sediment feeding decreases the bed elevation starts to decrease towards the upstream section (in the $40 \%$ of the channel length) but increases towards the downstream section (the remaining 60\%) of the channel. This is reasonable, since the transient bed profile moves downstream and thus concentration also increases downstream. For the postrecession period, the bed level decreases to the original level (equilibrium) at the upstream section, but as time progresses it increases towards the downstream section. Thus, the kinematic wave model seems to capture the expected behavior of the transient bed movement in alluvial channels, as seen in Fig. 7.
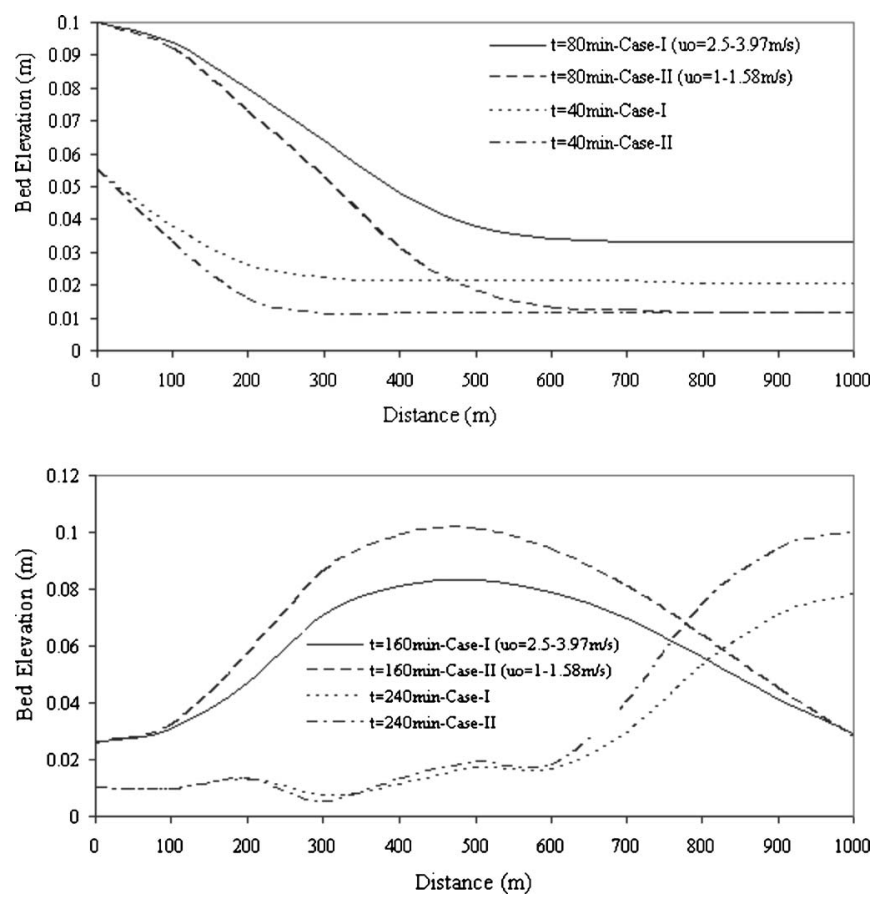

Fig. 8. Effect of flow velocity on transient bed form profiles during rising ( $t=40 \mathrm{~min}$ ); equilibrium $(t=80 \mathrm{~min})$; recession ( $t=160 \mathrm{~min})$; and postrecession $(t=240 \mathrm{~min})$ periods of inflow hydrograph and concentration 

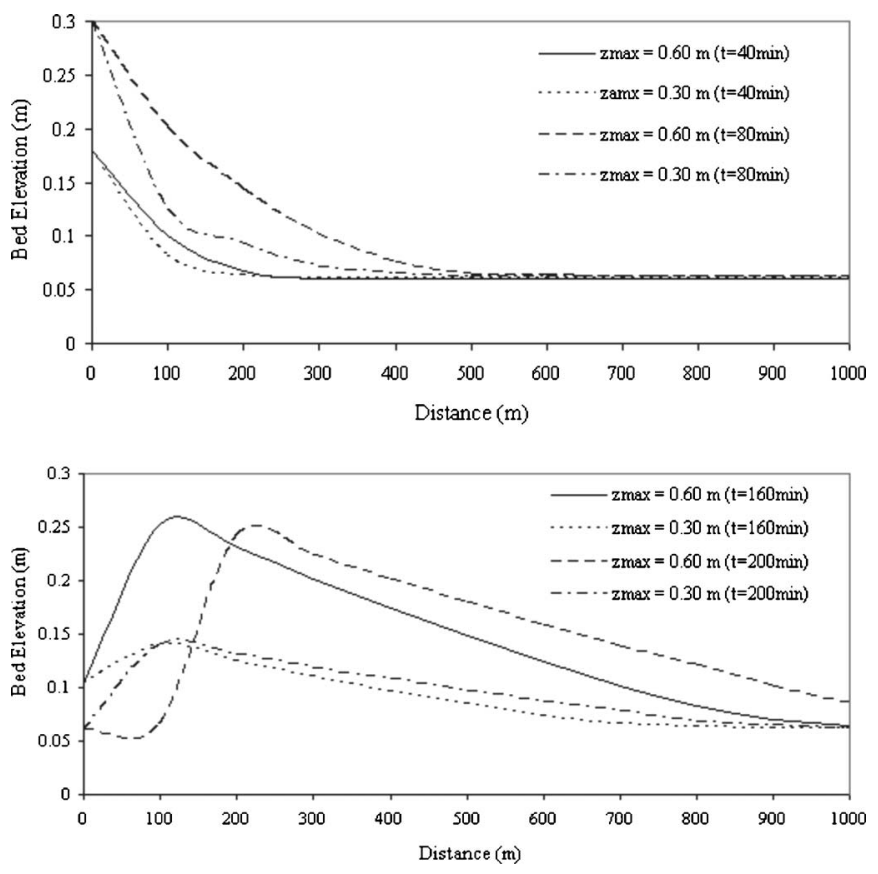

Fig. 9. Effect of $z_{\max }$ on transient bed form profiles during rising ( $t=40 \mathrm{~min})$; equilibrium $(t=80 \mathrm{~min})$; recession $(t=160 \mathrm{~min})$; and postrecession $(t=200 \mathrm{~min})$ periods of inflow hydrograph and concentration

The effect of flow velocity, and consequently, the velocity of sediment particles on the sediment waves are presented in Fig. 8. For this case, the same inflow hydrograph [Fig. 6(a)], but with an inflow base flow rate $Q_{b}=25 \mathrm{~m}^{3} / \mathrm{s}$ and inflow equilibrium flow rate $Q_{\text {eq }}=100 \mathrm{~m}^{3} / \mathrm{s}$ and the same sediment concentration inflow [Fig. 6(b)] were employed. The Chezy roughness and channel width were first assumed to be $71 \mathrm{~m}^{0.5} / \mathrm{s}$ and $20 \mathrm{~m}$, respectively, resulting in the change in the flow velocity from $u=2.5$ (base flow part) to $3.97 \mathrm{~m} / \mathrm{s}$ (equilibrium flow part) (Case-I), and then they were assumed to be $28 \mathrm{~m}^{0.5} / \mathrm{s}$ and $50 \mathrm{~m}$, respectively, resulting in the change in flow velocity from $u=1.0$ (base flow part) to $1.58 \mathrm{~m} / \mathrm{s}$ (equilibrium flow part) (Case-II).

Fig. 8 presents the effect of flow velocity on the transient sediment waves during the rising limb $(t=40 \mathrm{~min})$, equilibrium $(t=80 \mathrm{~min})$, recession limb $(t=160 \mathrm{~min})$, and postrecession $(t=240 \mathrm{~min})$ limb of the inflow hydrograph and concentration. For high velocity and sediment feeding at the upstream section, sediment particles move downstream faster, increasing the bed elevation along the channel length. For example, at $40 \mathrm{~min}$, under low velocity (Case-II) the bed wave front moved about $300 \mathrm{~m}$, while it had already reached the downstream end under high velocity (Case-I). At $80 \mathrm{~min}$, the bed levels close to the upstream end are almost the same but deviate toward the downstream end with higher elevation and faster speed under high velocity. During the recession limb, under low velocity (Case-II) the bed elevation in the middle portion of the channel is higher than that under high velocity (Case-I). This is because high velocity flow moves sediment particles faster towards the downstream section; thus, on the way the bed elevation reduces. On the other hand, since the sediment feeding is reduced at the upstream end, under low flow velocity sediment particles move slower, and consequently, bed elevation increases along the channel especially in the middle section. When there is no more feeding of sediment at the upstream section of the channel, the transient bed level would be expected to return to the equilibrium bed level starting from the upstream section and progressing towards the downstream end of the channel. Since sediment particles move slower under low velocity, it would take longer for the transient sediment wave to reach the original bed level. This is seen in Fig. 8, at $t=240 \mathrm{~min}$, where at the downstream end the bed elevation in Case-II is higher than that in Case-I.

The effect of maximum bed profile level on transient sediment waves is shown in Fig. 9. For this case, the inflow hydrograph that was used for investigating the effect of flow velocity on transient sediment waves was employed. The inflow concentration, shown in Fig. 6(b), was chosen but with an inflow base concentration $z_{b}=0.06 \mathrm{~m}$ and an inflow equilibrium concentration $z_{\text {eq }}=0.30 \mathrm{~m}$. Fig. 9 shows the effect of $z_{\max }$ on transient sediment waves at the rising $(t=40 \mathrm{~min})$, equilibrium $(t=80 \mathrm{~min})$, recession $(t=160 \mathrm{~min})$, and postrecession $(t=200 \mathrm{~min})$ periods of the inflow hydrograph and concentration. One would expect that under a greater value of $z_{\max }$ the transient bed profile would have a higher elevation and a faster wave front, because a greater $z_{\max }$ would allow a greater transport of sediment. This, in turn, would result in higher elevation of bed forms and sediment particles would move faster downstream. This expected behavior is clearly captured by the developed kinematic wave model.

\section{Conclusions}

Bed forms and/or bed sediment waves have been modeled in the literature using a multitude of hydraulic formulations that are based on some form of the St. Venant equations and conservation of mass of sediment in suspension and in bed. Depending on the assumptions employed, a hierarchy of formulations is developed, resulting in dynamic wave (hyperbolic) and diffusion wave (parabolic) approaches. The formulations have been mostly closed by a hydraulic resistance relation and a sediment transport function that has been expressed as a function of water flow variables. This study, however, as hypothesized by Langbein and Leopold (1968), showed that the movement of bed profiles in alluvial rivers can be modeled as a kinematic wave. The kinematic wave theory model employs a sediment transport function that relates bed sediment rate to sediment concentration (bed level). The model is successfully tested using data from laboratory flume experiments. Also, the simulations of transient sediment waves for hypothetical cases indicate that the kinematic wave model is capable of capturing the expected behavior of the bed sediment transport in field conditions.

\section{Notation}

The following symbols are used in this paper:

$c=$ volumetric sediment concentration in the water flow phase (in suspension) $\left(L^{3} / L^{3}\right)$;

$C_{b}=$ areal sediment concentration $\left(M / L^{2}\right)$;

$C_{b \max }=$ maximum areal sediment concentration when transport ceases $\left(M / L^{2}\right)$;

$C_{z}=$ Chezy roughness coefficient $\left(L^{0.5} / T\right)$;

$D_{c}=$ deposition rate $\left(M / L^{2} / T\right)$;

$E_{z}=$ entrainment rate (detachment rate) $\left(M / L^{2} / T\right)$;

$g=$ gravitational acceleration $\left(L / T^{2}\right)$;

$h=$ flow depth $(L)$;

$q_{\text {lbed }}=$ lateral bed load sediment $(L / T)$;

$q_{\mathrm{ls}}=$ lateral sediment flux $(L / T)$; 


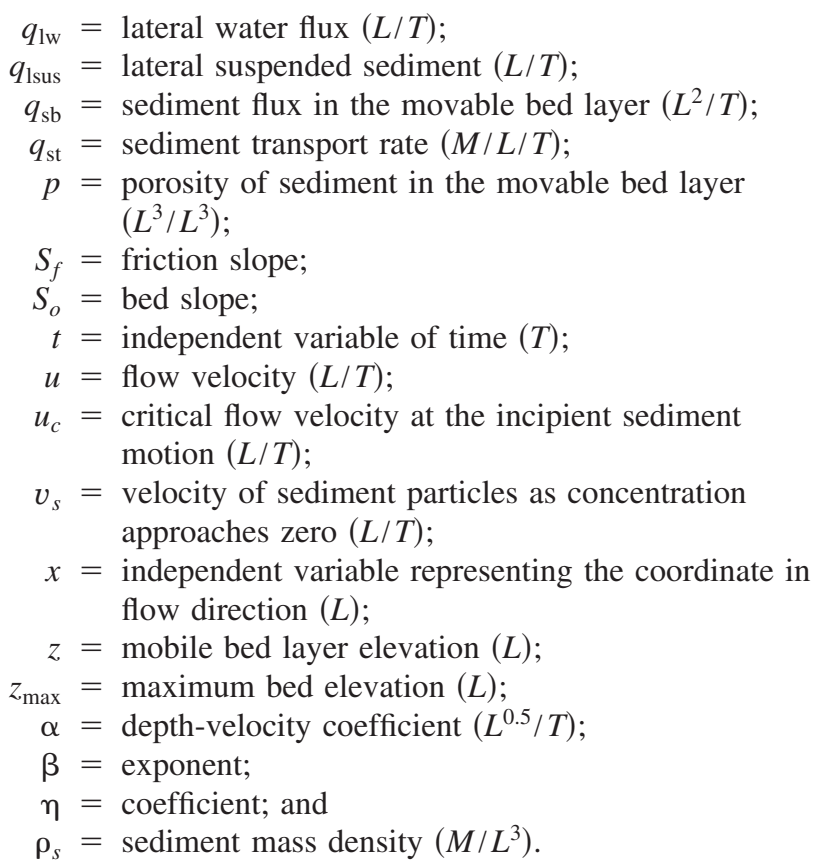

\section{References}

Bridge, J. S., and Dominic, D. F. (1984). "Bed load grain velocities and sediment transport rates." Water Resour. Res., 20(4), 476-490.

Cao, Z., and Carling, P. A. (2003). "On evolution of bed material waves in alluvial rivers." Earth Surf. Processes Landforms, 28, 437-441.

Cao, Z., Day, R., and Egiashira, S. (2002). "Coupled and decoupled numerical modeling of flow and morphological evolution in alluvial rivers." J. Hydraul. Eng., 128(3), 306-321.

Chien, N., and Wan, Z. H. (1999). Mechanics of sediment transport, ASCE, Reston, Va.

Ching, H. H., and Cheng, C. P. (1964). "Study of river bed degradation and aggradation by the method of characteristics." Chinese J. Hydraul. Eng., 5, 1-54.

Cui, Y., Parker, G., and Paola, C. (1996). "Numerical simulation of aggradation and downstream fining." J. Hydraul. Res., 34(2), 195-204.

de Vries, M. (1973). "River bed variation-Aggradation and degradation." Proc., IAHR Int. Seminar on Hydraulics of Alluvial Streams, International Association of Hydraulic Engineering and Research, New Delhi. de Vries, M. (1975). "A morphological time scale for rivers." Proc., 16th Congress of the Int. Association of Hydraulic Engineering and Research, Sao Paulo, Brazil.

Dietrich, W. E. (1982). "Settling velocity of natural particles." Water Resour. Res., 18(6), 1615-1626.

Guy, H. P., Simons, D. B., and Richardson, E. V. (1966). "Summary of alluvial channel data from flume experiments, 1956-1961." U.S. Geological Survey Professional Paper 462-I, U.S. Geological Survey, Reston, Va.

Hotchkiss, R. H., and Parker, G. (1991). "Shock fitting of aggradational profiles due to backwater." J. Hydraul. Eng., 117(9), 1129-1144.

Kassem, A., and Chaudhry, M. H. (1998). "Comparison of coupled and semicoupled numerical models for alluvial channels." J. Hydraul. Eng., 124(8), 794-802.

Langbein, W. B., and Leopold, L. B. (1968). "River channel bars and dunes-Theory of kinematic waves." U.S. Geological Survey Professional Paper 422-L, U.S. Geological Survey, Reston, Va.

Lyn, D. A. (1987). "Unsteady sediment-transport modeling." J. Hydraul. Eng., 113(1), 1-15.

Mahmood, K. (1975). "Mathematical modeling of morphological transients in sandbed canals." Proc., 16th Congress of the Int. Association of Hydraulic Engineering and Research, Vol. 2, Paper BB, 57-64.

Mohammadian, A., Tajrishi, M., and Azad, F. L. (2004). "Twodimensional numerical simulation of flow and geomorphological processes near headlands by using unstructured grid." Int. J. Sediment Res., 19(4), 258-277.

Pianese, D. (1994). "Comparison of different mathematical models for river dynamics analysis." Proc., Int. Workshop on Floods and Inundations Related to Large Earth Movements, Trent, Italy, October 4-7, Paper No.782.

Ribberink, J. S., and Van Der Sande, J. T. M. (1985). "Aggradation in rivers due to overloading-Analytical approaches." J. Hydraul. Res., 23(3), 273-283.

Singh, A. K., Kothyari, U. C., and Ranga Raju, K. G. (2004). "Rapidly varying transient flows in alluvial rivers." J. Hydraul. Res., 42(5), $473-486$

Singh, V. P. (1996). Kinematic wave modeling in water resources: Surface water hydrology, Wiley, New York.

Soni, J. P. (1981). "Laboratory study of aggradation in alluvial channels." J. Hydrol., 49, 87-106.

Tayfur, G., and Singh, V. P. (2006). "Kinematic wave model of bed profiles in alluvial channels." Water Resour. Res., 42(6), W06414.

Vreugdenhil, C. B., and de Vries, M. (1973). "Analytical approaches to unsteady bedload transport." Research Rep. 578, Delft Hydaulic Laboratory, Delft, The Netherlands.

Yang, C. T. (1996). Sediment transport theory and practice, McGrawHill, New York. 